\title{
KHAN ACADEMY: THE ILLUSION OF UNDERSTANDING
}

\author{
Marc Schwartz
}

University of Texas at Arlington

\begin{abstract}
This paper examines the ongoing challenge of defining what learning means from the perspective of the cognitive and learning sciences, especially as it unfolds in on-line environments. To better define learning as well as offer guiding principles, this paper uses Khan Academy as an example of what some highprofile individuals, such as Bill Gates, are claiming to be the future of education. I offer five guiding observations that provide a structure for understanding the learning process and apply them to Khan Academy as a means of revealing what I call the illusion of understanding, and I replace that view with a more authentic understanding of the learning process and the means to achieve that understanding.
\end{abstract}

\section{KEYWORDS}

Khan Academy, cognitive development, hierarchical understanding, practice, feedback, context sensitive

\section{INTRODUCTION: THE ILLUSION OF UNDERSTANDING}

A serious challenge for educators and students is avoiding what I call the illusion of understanding. Most often, the illusion arises when educators and students fall into the following relationship: "I'll pretend to teach as long as you pretend to understand." The interaction is neither malicious nor necessarily conscious. In fact, the relationship emerges out of a persistent and pervasive misunderstanding of the learning process, one repeated in numerous contexts throughout the history of education, apparent in the introductions of textbooks over the last 150 years (which justify the newest and latest textbook), and now repeated at Khan Academy. Recognizing the relationship in educational contexts is challenging because educators are embedded in the process and, if they are reading this article, are most likely a product of the process. But the effort is necessary if we are to understand and address our misconceptions about teaching and learning and, more importantly, to avoid succumbing to the illusion that real teaching and learning is occurring.

\section{A. What does the illusion of understanding look like?}

An illustration from my own work of the illusion of understanding occurred years ago when my colleagues and I were training as science educators in a graduate course at the Harvard Graduate School of Education (Schwartz and Fischer 2003). A significant part of the course involved students addressing a number of problems involving basic principles of science. The problem students found the most intriguing is the following:

Imagine you come upon a canoe in a swimming pool and you remove the large anvil you find in the canoe and submerge the anvil in the pool. If you note the level of water before commencing the operation and again after the anvil is completely submerged, does the water level of the pool change?

This question, describing an unlikely situation, might have created some dissonance, but our students were well embedded in the process of answering similar questions and accepted the challenge. You might want to consider this problem as well before reading further. This scenario was created to challenge students' understanding of Archimedes' principle, a concept found in many school curricula around the 
world. At Khan Academy, this principle is directly addressed in two of twelve sessions on "Fluids" (parts five and six): http://www.khanacademy.org/science/physics/fluids/v/fluids--part-5

What you should note about the canoe scenario is that it can be solved entirely without mathematics. The problem is purely conceptual and has just three possible solutions: the water level will go up, remain unchanged, or go down. For five years my colleagues and I posed this and similar challenges to students, and, surprisingly, for five years the distribution of their answers appeared to be no better than as if by chance.

\section{B. What does the illusion of understanding feel like?}

Students were also surprised, although unpleasantly, at their inability to arrive at a definitive answer to the canoe problem. They thought they understood Archimedes' principle until they faced this or similar conceptual problems to which they had to apply the principle. The level of distress these problems created for students surprised us. Some expressed a feeling of panic at the thought that if they didn't understand this principle, perhaps they didn't understand anything they had learned in school. This was perhaps the most surprising insight for us: we are all subject to the illusion of understanding until we are somehow forced to face it. But the most insidious aspect of the illusion of understanding is that it masks what I will call authentic understanding.

\section{What is authentic understanding?}

Over time, my colleagues and I learned to appreciate a small number of important observations about the nature of authentic understanding that distinguishes it from the illusion of understanding. The observations are straightforward, but the nuances of each make them easy to dismiss because they are hard to integrate into what many educators, including Khan, believe understanding to mean. To be fair, those educators' views are not often explicitly stated but are revealed through their choice of interventions and assessments. Meeting this challenge is not trivial.

Understanding is a complex phenomenon. While difficult to define or measure precisely (Elgin 2006), it is nonetheless possible to identify key characteristics and processes that support its development. The insights and recommendations that follow have emerged not only from my own observations but also from the work of numerous cognitive scientists, neuroscientists, and educators over the past century (Bransford, Brown, and Cocking 2000; Elman et al. 1996; Klahr In Press; Perkins 1992; Piaget 1985; Posner and Rothbart 2006; Powers 1998; Siegler 1996; Schank 2011; Schwartz 2009). Here, I describe five critical insights concerning the nature and development of authentic understanding. The insights help confront the illusion of understanding, which continues to survive and thrive in a variety of educational contexts. Khan Academy is just the latest reminder of our collective struggle to profit from the learning sciences; however, more challenging in the context of the virtual classroom is that the teacher-student relationship cannot profit from even the most basic form of communication-the student's confused look. As everyone stares at the magic Smartboard, the illusion that Khan is teaching and that the observer is learning is that much easier to perform.

To be fair, the problem inherent at Khan Academy is one that appears in many educational contexts, and the academy's potential strengths are noteworthy, but not because they necessarily support authentic understanding. As Khan highlights in interviews, the central issues he addresses are student attention span, the availability of instruction, and student control of the pace of instruction. While these features allow students to more easily consume videos intended to be instructional, they are nonetheless peripheral to the goal of developing students' authentic understanding.

\section{FIVE KEY OBSERVATIONS ABOUT AUTHENTIC UNDERSTANDING}

The following five observations offer a working framework of authentic understanding:

- Authentic understanding depends on hierarchically organized knowledge.

- Authentic understanding is grounded in direct experience. 
- Authentic understanding is stabilized by practice (generally at every level within the hierarchy).

- Authentic understanding requires formative feedback.

- Authentic understanding is context-sensitive.

The generality of these criteria is supported by the fact that our students were extremely bright, motivated, and often just as surprised as we were by their inability to leverage the formulas they had learned by heart and used for years in science classrooms to solve problems. Dismissing our students' struggle with the conceptual problems as being peculiar to them was not easy, as they were considered to be among the best in the nation. Thus, the first important realization was that intelligence had little to do with the challenges the students were facing. In any situation in which these five criteria are ignored, understanding becomes fragile and unstable, and our ability to recall or apply what we remember is compromised.

\section{A. Observation one: authentic understanding depends on hierarchically organized knowledge.}

Understanding, the nature of which has been unpacked by over a century of research, is hierarchical in structure (Case 1987; Commons et al. 1998; Fischer and Bidell 1998; Piaget 1983; van Geert 1998; Dawson-Tunik et al. 2005). Each new achievement within the hierarchy becomes the foundation for the next more complex, more integrated coordination of earlier achievements. The work of Piaget and scores of Neo-Piagetian scholars have documented this process, in which sensorimotor experiences (i.e., what we learn through our senses) become the foundation for representations of the content of experiences (e.g., words, pictures, graphs, tables, etc.), and later those representations are coordinated into abstractions that transcend the concrete nature of our experiences and the representations and relationships that emerged earlier from our sensory experiences. Thus, abstractions, such as democracy, justice, or Archimedes' principle, emerge as a new way of understanding the rich coordination of representations accumulated through various contexts and practiced on multiple occasions. However, this achievement, which is the outcome of a powerful synthesis of concepts, is often belied by simple-looking words and phrases like "democracy" or "Archimedes' principle," which at face value do not appear to be remarkably different from other words students use, such as "gavel" and "anvil."

All of the three tiers (sensorimotor, representation, and abstraction) are qualitatively very different ways of understanding, and each depends on the earlier tier to achieve the more complex understanding of later tiers. Progress for students is, however, more nuanced than what is captured by these three major developmental steps. Within each tier researchers have noted finer degrees of achievement, described as levels (Commons et al. 1998; Dawson-Tunik et al. 2005; Fischer and Bidell 1998; Schwartz and Sadler 2007). For example, the first level of the representational tier signifies the ability to name objects, such as the object in the canoe (i.e., the anvil). The next level (in the representational tier) involves coordinating exemplars from the first level into a new understanding, such as knowing that putting the canoe (or any object) into the pool will raise the water level. There are still two more levels of complexity in each tier that require additional exemplars of earlier levels as well as further coordination before moving to the next tier. The transition to the abstract tier requires the consolidation of representational skills from all four levels into a qualitatively new way of thinking about the world, which is summarized in words such as "justice," "democracy," or "Archimedes' principle." Details regarding the nature of levels and tiers, their structure and relationship to each other, the criteria for measuring the complexity of each level, and movement from one level to the next are well documented and illustrated by numerous researchers (Dawson-Tunik et al. 2005; Fischer and Bidell 1998).

For the purposes of this article, there are two important notions about any skill demonstrated at any level in any tier. First, the skill is observable, which is of particular importance to educators and students. Second, movement up the hierarchy involves the coordination of less complex skills into skills of greater complexity, like a juggler adding more objects into a juggling routine. As skills become more complex, the coordination becomes increasingly more complex. Time and practice will allow for some 
consolidation of earlier skills into more stable skills of greater complexity. However, as every juggler knows, practice is necessary to maintain the coordination of plates, balls and knives; otherwise ideas, like objects, crash to the ground.

\section{Do Khan Academy lessons support the development of hierarchical knowledge?}

Looking at Khan's series of videos related to Archimedes' principle as a representative example, the layout of the lessons is not compatible with the observation that humans build knowledge hierarchically. For the most part, he introduces ideas at the most complex levels of the representational tier or the next higher tier (i.e., abstraction). While it is true that the video is sensitive to sequencing concepts, the work is done from the perspective of an expert. This is an important distinction.

The expert's perspective offers a global view of relevant concepts, the heuristics to understand relationships between concepts, and the algorithms that reveal more precise understandings of those concepts. From this vantage point, the expert sees the educational challenge as unpacking complex skills into less complex skills. Thus, it would make sense from an expert's point of view to introduce density before discussing Archimedes' principle, which depends on density. This approach generates a sequence of abstractions relevant to the expert, but not a sequence that the learner can necessarily construct or see as relevant.

Learners typically confront a different challenge-one of building more complex understandings, as encountered in higher levels and tiers. Every graph, formula, drawing, and arrow on Khan's Smartboard is a relevant representation (otherwise it wouldn't be in the video); however, he unconsciously ignores the sequences of experiences that allow students to coordinate or juggle these (and other necessary) representations into concepts like density and, eventually, Archimedes' principle.

One important exception to this general observation is the "Knowledge Map" in the area of math. While the map is very important in understanding the development of a discipline, the map is not a picture of the development of understanding in individual learners. It is important to note that while the map is a hierarchical framework, the hierarchy emerges from the perspectives of experts, not learners. Similar work can be seen in the Atlas of Science Literacy (AAAS 2001). Here the authors claim something more explicit: "[The] Atlas of Science Literacy is a two-volume collection of conceptual strand maps ... that show how students' understanding of the ideas and skills that lead to literacy in science, mathematics, and technology might develop from kindergarten through 12th grade" (1).

This claim is seductive. The actual path to understanding might be broadly marked out by these maps (as indicated by the authors), but this work was accomplished by experts retrospectively reflecting on how they learned science, so we must emphasize that they do not necessarily characterize how students actually build that knowledge. In similar fashion, the math Knowledge Map connects a number of relevant topics, beginning with addition and subtraction and ending with calculus, and within each topic there are exercises that test student understanding. I will underscore here and beyond that the knowledge map as well as the Atlas of Science Literacy offer an important perspective on the development of a discipline, but whether the maps lead students to authentic knowledge is not obvious, thus we must be circumspect with how we use these maps to create interventions and assessments in the belief that students are re-creating the same understanding as experts.

\section{B. Observation two: experience is the foundation of authentic understanding.}

Educators recognize the importance of creating experiences, but it is important to note that not all experiences are equal. Central to the first observation is that understanding develops first through the use and integration of our senses. Formulas for concepts like density or pressure $(d=m / v$ and $p=m g h)$ belong to the representational tier and are far removed from the senses that students need to immediately coordinate and employ when confronting a new and complex juggling routine. While many elementary or middle school curricula do incorporate activities such as submerging small blocks of iron or wood to see how much water is displaced, such experiences are too remote and inaccessible to high school students trying to understand how the laws and algorithms their teachers are using encapsulate their earlier 
Khan Academy: The Illusion of Understanding

experiences. The power in laws and principles is in the fact that they summarize numerous experiences, but those insights cannot be transferred directly from one person to another-the abstraction, divorced from the numerous experiences that gave rise to it in the first place, is lost upon the student who doesn't have the foundation of experiences that give rise to personally constructed representations, which in turn will support the abstractions valued by educators.

The task of teaching begins in carefully choosing experiences that challenge the student's intuition about the world, and allow for numerous interactions between the student, their experiences, and the challenges they are facing. This dynamic process, which requires time and multiple opportunities to engage with the content, is necessary to develop more complex representations (Doucerain and Schwartz 2010; Schwartz and Sadler 2007). Eventually, this kind of work can set the stage for watching and appreciating the complexity in Khan's juggling of representations such as pressure, volume, gravity, etc., embedded in parts five and six of "Fluids."

\section{Do Khan Academy lessons ground complex ideas in sensorimotor experience?}

Like many accomplished science educators, Khan demonstrates his ability to coordinate numerous representations, which is analogous to observing a master juggler. Watching Khan carry out a complex performance of understanding in 15 minutes or less is also much like watching a professional musician play a piece of similar duration. In this case, audience members do not generally believe themselves capable of reproducing the same performance afterward. However, what is curious in educational contexts is that after listening to a lecture, teachers and students frequently believe that the student should be capable of performing at the same level as the teacher and with the same level of authentic understanding. But that isn't the case, even after students spend time on questions, algorithms, charts, and graphs found on worksheets or at the end of the chapter. Just practicing within the representational tier doesn't appear to support authentic understanding.

One promising aspect of Khan Academy is the effort to develop authentic understanding through intuitive practice, again in the area of math. The technology embedded in the problems allows students to experiment with the impact of different variables that give rise to important concepts, such as standard deviation or average; however, changing the distribution of data on a two dimensional graph, for example, still requires focusing on juggling representations and not yet how the representations connect to tangible experiences. Authentic understanding requires a wide platform of experiences, which in turn provides a foundation for the representations that are the basis of student work in any school environment, virtual or real. Without the benefit of this foundation, representations practiced in school are reduced to borrowed ideas that are limited in scope and decay rapidly (Schwartz and Fischer 2003).

\section{Observation three: authentic understanding is stabilized by scaffolded practice.}

Students who can recall the formulas they practiced using in school often struggle to employ those formulas outside the rigid contexts in which they were learned (Fischer et al. 1993; Lave 1993; Nardi 1996; Wertsch 1984; De Corte 2012). Such was the case with my students. Their knowledge of the formulas left them with an illusion of understanding, which unraveled when they confronted conceptual problems based upon the related algorithms. Formulas are important tools that mathematically represent relationships observed in nature. They often show up in demonstrations as a way of expressing complicated relationships, but they do not necessarily reveal the conceptual basis for the relationships between the variables or the numerous experiences underlying the formula, no matter where they appear-classroom whiteboards or Khan's Smartboard.

Khan's presentations look no different from what many practiced physics teachers create for their students even though the duration may be much shorter in Khan's case (see reference section for other, longer, examples). Demonstrations that illustrate the teacher's understanding also reinforce the illusion of understanding (Tai and Sadler 2007). The viewer watches the instructor demonstrate the outcome of years of their own practice, creating for students the afterglow of an experience in which meaning was created, 
but not by the student.

Students who report having trouble following demonstrations also report that they quickly lose interest; thus, it is not surprising that the short attention span that Khan highlights as a universal educational problem becomes a defining feature of his presentations. Educators must address the disconnect students experience between their current understanding and the demonstration they are observing, which includes the less obvious knowledge embedded in the instructor's choice of objects and tools, as well as the order in which both are used and manipulated during the demonstration.

One approach we used to address the disconnect mentioned above was through the kinds of problems we offered students. We found that without instruction or encouragement students would take control of problems and practice with them at home, using whatever tools and supplies were available to them. They surprised us by returning to class explaining what they had learned. While we were impressed by individual performances of understanding, we unfortunately remained vulnerable to the illusion of understanding. Initially, we succumbed to the easy belief that the students listening to these stories of success had also achieved the same level of juggling demonstrated by their peers, but they quickly punctured that illusion. Some quickly announced that they didn't understand what their peers had said, and did not understand until they attempted the demonstration. Then, in their own words they tried to explain what they understood. In effect, authentic understanding emerged as a process of students juggling the ideas and tools on their own. The ongoing challenge educators must face is identifying demonstrations that challenge their students' intuition and inviting them to assume control and practice juggling the relevant elements of the demonstration.

Our students learned that they had to practice re-presenting their explanations so that their complex ideas could develop stability over time. In one dramatic moment, a student correctly described what would happen to the water level in the pool, but then paused, looked at the class, and publically admitted he didn't understand what he had just said. For several minutes he had created and sustained an understanding that allowed him to see the causal connection between his experiences and representations and what would happen to the level of water in the pool. But he also realized that the understanding was temporal. Understanding does not sit in our minds like books on shelves (Fuster 2009). We have to recreate understanding so that it can achieve some level of permanence. But as jugglers know, if they don't practice there is little guarantee they can pick up the blocks (or concepts) and begin juggling again.

It is useful to practice with the same problem a number of times, like a musician practicing the same piece until she is comfortable with every aspect of the score. An important dimension of practicing is that the learner can easily observe changes in performance over time. The notes become easier to play; there are fewer mistakes and greater fluidity, etc. As with the canoe problem, practice allows the student to recognize the importance of volume or how the impact of volume on the water level is different when evaluating the role of the canoe and the anvil (before it is removed from the canoe). Similarly, the mass of the anvil plays a different role (on the outcome of the water level) depending on whether it is in the canoe or in the water. Coordinating these ideas into a more complex representation is a necessary foundation for achieving new abstractions (such as Archimedes' principle).

\section{Does Khan Academy scaffold practice?}

There are currently a limited number of subjects taught at the Academy that offer opportunities to practice. The sole area in which practice is offered, which is particularly well developed, is mathematics; however, as pointed out earlier, practice is limited to the representational tier. While scaffolding is provided within this tier to help students unpack, for example, the meaning of median or mode, this work is executed through the use of other representations. There are no explicit connections to relevant experiences that students can use to construct for themselves authentic representations at any level. The risk, as noted earlier, is that students are left with an illusion of understanding that is fragile and highly context specific (a problem explored in observation five) and disconnected from the real world.

Outside the area of math, as in the case of "Fluids" and Archimedes' principle (parts 5 and 6), practice is not yet an option. As the Academy creates practice conditions for students, there are two important 
Khan Academy: The Illusion of Understanding

considerations. First, practice must focus on the careful choice of similar problems (like musical compositions that feature the same technical challenges like rhythm) that reinforce the skills used and afford greater comfort with concepts, such as volume and mass (or notes, rhythm, and intonation, as the case may be). Problems similar to each other in scope and complexity are instrumental in allowing students and teachers to consider the important role context plays in teaching and learning. Second, practice must lead to meaningful feedback. Feedback not only helps adjust performance as a skill is stabilized, but it should also provide the platform for reaching the next more complex level of understanding.

\section{Observation four: meaningful feedback is relevant and timely.}

All life depends on relevant feedback. This is true across a range of complexity beginning with single celled organisms looking for nutrients, to multicellular organs achieving homeostasis, to multicellular organisms attempting to survive in their niche. Relevant feedback for students and educators is generated through actions they believe will allow them to achieve a particular goal. Students need to recognize the target they are attempting to reach and be able to identify likely responses they believe will lead them to success. More importantly they need the freedom to try out those actions. Only in the context of attempting to achieve a goal do our actions make sense, and only then can we meaningfully interpret the outcome of our actions (Langer 1997; Powers 1973; Schank and Cleary 1995). While this might seem obvious, executing this in educational contexts is challenging.

This task of identifying goals that students understand and that also match their current ability to juggle is not easy but necessary. A number of researchers have pointed out that lessons need to be strongly guided by goals that focus a student's attention (Langer 1997; Perkins 1992; Powers 1998; Schank and Cleary 1995). An effective goal provides students with the opportunity to identify promising strategies to reach the goal, which in turn creates a meaningful foundation for creating and coordinating more complex representations and abstractions.

The problem with school lessons whose "goals," for example, require students to submerge blocks of iron or copper or wood in a column of water is that for many students there is no obvious or explicit reason for the activity. Students should be asking, what is the problem for which this lesson (i.e., submerging blocks) is the solution? But students don't ask this question because they are more accustomed to asking how they should participate. Thus, the likelihood of recognizing the need to ask why Khan is making the choices he makes during his video presentation is even more remote. It may not be clear to a student what goals are guiding Khan's actions. At times Khan's indecision is obvious in that he will start a drawing and then change his mind and start something different. Why? What problem was he facing that required a change in teaching strategy? This style of teaching is not unique to Khan, as the teaching environment is dynamic. Teachers often change their minds and approaches as they become involved in the teaching moment. The energy and creativity that often characterize these moments easily support the illusion of understanding, as the learner experiences the theater of the teacher's goals successfully directing the teacher's actions. Unfortunately, the learner is often too passive during the whole experience. More dramatic is the online experience, which creates a new challenge in that the "teaching moment" is not really shared with the audience or influenced by it. As the dynamic nature of teaching becomes codified, the video risks becoming a permanent reminder of the distance between the instructor and student, further reinforcing the need to passively observe. As passive observers, students eventually let go of asking why any demonstration (of the teacher's expertise) is unfolding as it is, because students know they will not be answered.

To confront this challenge, instructors need to consider how to set up problems that have clear actionable goals, and that action on the part of students generates feedback that is meaningful to them, thus requiring less feedback from the instructor. In regard to the canoe problem, one should note that nature, rather than the instructor, provides the feedback. Students don't need to ask the instructor what the answer is, although they often will. In these cases the instructor can direct students to find the answer on their own in the lab or at home. 
Finding problems like the canoe problem also provides students with the opportunity to consider the importance of their own work in creating new knowledge. These kinds of problems can provide high intrinsic motivation similar to state of "flow" (Csikszentmihalyi 1990) in which the sense of time compresses, focus and concentration increases, and distractions disappear. The experience is also similar to what individuals experience when playing certain video games (Schwartz and Sadler 2001).

In contrast, extrinsic motivation is what educators use when students don't respond in ways intended by the lesson. This situation can result from a number of problems: students don't understand the goal, don't recognize the appropriate action, don't have the ability to execute the required action, or can't interpret feedback generated by their action (or given by the instructor). Extrinsic feedback often depends on rewards (such as money, grades, extra time at recess, less homework, etc.) that are unrelated to the goal of making students want or need to create more complex representations or abstractions. Extrinsic feedback is less powerful at generating more complex understandings, as observed by drivers who get information about how to drive from the person in the back seat. The risk of a system based upon extrinsic rewards is that it easily contributes to the illusion of understanding.

\section{What does feedback look like at Khan Academy?}

Like many school environments, Khan Academy depends on extrinsic feedback, in which students receive "badges" and "energy points" after completing lessons. If they wish, students can share with selected audiences their progress through the lessons. Second, students can also ask questions in a blog format, to which other members of the Academy can respond. It's not clear that answers from the community are any more helpful than Khan's videos or my students' explanations of their understanding to their peers.

Both forms of feedback fall short of what counts as meaningful and timely feedback. Badges do not contribute to developing an understanding of fluid dynamics. I, for example, earned three badges while watching "Fluids"; however, those badges are not predictors of how successful I would be with the canoe problem or variations of the canoe problem or any similar problem in a new context (e.g., applying Archimedes' principle with gasses instead of fluids).

The third form of feedback, developed as part of the math Knowledge Map at Khan Academy, is embedded in the available practice problems. The software evaluates the student's answer, and if the answer is incorrect the software offers one or more layers of suggestions that guide students to the right answer. Alternatively, the student can choose to unpack the layers without committing to an answer, and teachers can follow student progress.

This form of feedback resembles coaching, in which students are provided with specific support in response to a problem in executing a skill. While coaching can help students achieve greater proficiency with skills or practice more effectively, the more basic challenge of developing authentic knowledge remains. If the short-term goal is for students to get better at solving quadratic equations, then they may never discover the problem for which the quadratic equation was the solution in the first place. Developing a richer palette of sensorimotor experiences that are tightly linked to representations still needs to occur before teachers become overly focused on training students to solve quadratic equations. Otherwise the students' work becomes no more important or useful than a parlor trick restricted to very specific contexts. This challenge is already one that teachers find difficult to meet in classrooms and, expectedly, much more challenging in an online environment.

One possible solution is letting the video set up problems that students can execute on their own and in turn allow them to judge the impact of their actions. In our case, the problems we posed students provided this opportunity. In turn, course instructors began to play a more marginal role in providing answers because nature could offer immediate feedback. Given this kind of experience, our students were better able to adapt to situations where nature could not conveniently respond to their questions. In such cases, students were better prepared to consider the answers of experts, and to compare them to their own. In situations where nature cannot provide an answer, current technology can collect student responses and allow them to compare and contrast answers through graphs or tables that are continually updated. A 
Khan Academy: The Illusion of Understanding

distribution of student answers has the potential to encourage students to take a deeper look at the original challenge and the answers.

\section{E. Observation five: authentic understanding is context-sensitive.}

While practice provides opportunities to challenge the stability of a complex idea, practicing in a variety of contexts challenges the robustness of one's grasp of the principle underlying any particular problem. Thus, initially the juggler may be comfortable juggling balls in front of friends, but the same act on stage in front of strangers can create a different experience and result. In this case, changing contexts where competence is demonstrated will challenge how easily ideas - or balls-are coordinated. While there is value in establishing this kind of stability with a problem, the greater challenge is establishing stability with the principle behind related but novel problems (Fischer et al. 1993; Granott, Fischer, and Parziale 2002; Griffin 1995; De Corte 2012).

The canoe problem offered students the chance to practice and demonstrate their understanding through different approaches. Inviting students to demonstrate their understanding through writing, oral presentations and, in turn, using their understanding with their students created stability with this one problem, but not necessarily with Archimedes' principle. Developing comfort with Archimedes' principle requires changing the problem in slight ways to provide students the opportunity to challenge their understanding. For example, changing the context slightly by asking what would happen to the level of water if the anvil were replaced with a large piece of foam or a piece of balsa wood or a smaller version of the anvil allows students to focus on particular elements of a problem growing in familiarity. Working with the original problem provides a framework that remains constant over time so students can control elements within the problem to judge the importance and role the variables (such volume, mass, floating, sinking, etc.) play.

After a trial period during which students explore the impact of the variables in the problem, the curriculum can invite students to consider new and unfamiliar contexts where the principle is still operating. Consider for example a planet like Mars where the atmosphere is predominantly carbon dioxide. If an astronaut fills her birthday balloon with oxygen and releases it, will the balloon fall, float in place, or climb? Although this problem requires an understanding of chemistry, the example illustrates the kind of opportunity that educators need to create in which students can consider how Archimedes' principle is operating. Problems like this already exist in numerous textbooks (Epstein and Hewitt 1981; Hewitt 2010); however, to make effective use of such problems, careful and purposeful attention to the earlier observations is still necessary.

The experience students had with the canoe problem allowed them to begin considering more modest changes in context. Asking students what variables they would change, and to consider the impact of those changes, invited students to take ownership of the problem. The shift in responsibility for the problem as well as the answer offers a unique opportunity to explore the role of feedback, in that students are now looking for answers to their own questions.

\section{Is the curriculum at Khan Academy context sensitive?}

All academies of learning, including Khan Academy, face the challenge of how to vary the goals in meaningful ways to allow students to evaluate how robust their understanding is. The virtual environment provides the unique opportunity to layer numerous dynamic contexts to create a foundation of understanding that leads to multiple applications of the principles being studied. Much of the material necessary is already available on the web as products of teacher inventiveness to help students understand the plethora of concepts now required for state testing. Building on this work while maintaining attention to all five observations is a challenge not just for Kahn but for all educators.

This issue is especially relevant as universities try to reach larger audiences through Massive Open Online Courses (MOOCs). The courses organized through initiatives such as edX or Coursera seek to distribute "understanding" to hundreds of thousands of students. But new educational environments such as these are not immune to the observations noted as necessary for authentic learning. For example, the common 
use of multiple-choice exams and peer evaluations falls far short of creating effective feedback. While the outcome of the MOOC experiment is still hard to gauge, without a meaningful framework of learning, they are unlikely to succeed, a situation already noted by the press (Rees 2013; Wilson 2013; Koh 2013). Currently, completion rates hover around 10 percent for most MOOCS (Jordan 2013), which may be a signal that students are aware of the illusion of understanding and are looking elsewhere for a meaningful learning experience.

The tools of technology do offer educators and students a future that is both promising and complex. The revolution in education that Bill Gates describes when referring to Khan Academy is based upon the power of magnification that technology offers; but a technological platform that claims to "provide a free world-class education for anyone anywhere," as Khan Academy promises, still requires understanding how students learn as well as how to effectively evaluate the impact of instruction at the individual level. Gates' experience in technology is noteworthy, but the thousands of hours of practice and feedback that unfolded as he pursued his goal of understanding computers is unique (Gladwell 2008); thus, educators must be careful with how individual experiences and perspectives such as his are leveraged when making educational decisions, especially decisions that will impact the millions Gates wants to help. While he does recognize that caution is necessary and that placing a video in front of a captive audience is not a universal solution for educators and students (Gates and Microsoft 2013), Gates' background does not reasonably support the level of analysis required, nor the ability to identify the most promising solutions, without his also having dedicated thousands of hours to studying teaching and learning.

Thus, the temptation is to quickly overreach with the use of technology without seriously considering the implications for students and teachers. For example, this year Carlos Slim, the Mexican telecom entrepreneur, agreed to provide the resources to translate Khan academy into Spanish, but whether Khan's representations and personal experiences will cross the cultural divide will be a real test of how context sensitive the videos are. I'm reminded of a lecture I gave years ago in Quebec, Canada, where I introduced the canoe problem. Several individuals asked me what an anvil was, and I referred to the Looney Tunes episode "Going! Going! Gosh!" in which Wile E. Coyote tries to drop an anvil on the Road Runner (Wikipedia 2013). The audience feedback was immediate. Blank stares informed me I was either outdated or culturally out of touch, and I needed to try again.

\section{CONCLUSION-THE ILLUSION OF UNDERSTANDING}

Unfortunately, there is no way that this paper, which has taken much more than 15 minutes to write and read, will convince anyone that they now understand what we had to observe repeatedly, practice constantly, and evaluate through feedback from our students over years. Educators must apply these observations every day, just as musicians and artists practice every day to become masters of their crafts.

The observations noted in this paper will still be easily discounted by strong intuitions about teaching and learning developed over years as a result of surviving an educational system that is and has been mostly didactic. Factors such as the lack of time or resources will easily undermine the need to carefully scaffold experiences that allow students to build more complex understandings. Those factors undermine the importance of developing student experiences as a foundation for new representations or a new coordination of familiar representations. They weaken our resolve to encourage students to practice or seek new contexts in which student understandings can be challenged. And perhaps the most pernicious outcome of a pedagogy based on the lack of time, resources, or student feedback is that students become dependent on their instructor's feedback to judge their success, and instructors miss the opportunity to recognize and develop lesson goals in which student action becomes a source of feedback that students use to judge their success in learning.

Our students had mastered numerous tests of knowledge over many years and demonstrated their skill in using formulas learned in numerous carefully constructed contexts such as books, problem sets, and tests. This work did not provide them with the conceptual understanding underlying a basic principle in the sciences. Perpetuating the illusion of understanding with students is an easy trap for instructors to fall into whenever they assume that they are responsible for the entire feedback loop. Instructors need to focus on 
carefully chosen goals that challenge a student's intuition, and, in turn, allows that student to complete the feedback loop largely on their own.

This operation will of course challenge the instructor's intuition about what teaching means. Khan, like many educators, falls victim to this illusion in his teaching, partly because he doesn't get the kind of feedback that forces educators to challenge their assumptions about learning. Bill Gates and Sal Khan are not alone in using their experiences as the lens through which they understand and respond to educational problems. Using experiences for decision-making is natural and to be expected when creating understandings (a point made repeatedly throughout this article). However, despite the "naturalness" of such actions, the risk we face collectively is of making educational decisions that ignore the last hundred years of cognitive science and emerge predominately from our intuition, a strategy that is usually ineffective (Kahneman 2011). Shortening demonstrations to match an ever-shrinking attention span or creating a plethora of on-demand videos completely misses the shift in perspective necessary to expose the illusion and allow teachers and students to make the adjustments necessary to support and develop authentic understanding.

\section{NOTES}

1. The word "representation," as used here, focuses on the act of "re-presenting" as in re-enacting or recreating understanding, and also intentionally underscores the ability to reproduce the same understanding at a later time.

\section{ACKNOWLEDGEMENTS}

I wish to recognize my colleagues who read and commented on this piece as well as encouraged me to write it: Mike Connell, Eugenia Garduno, Irwin Shapiro, Bruce Gregory, Jeanne Gerlach and Ken Williford. I also want to recognize my students who read drafts of this paper and interacted with me over time on the observations noted in the article. The input of all these individuals led to a stronger, more focused framework for the challenging work that all educators face. I am also thankful to Gary Miller who saw a purpose and need to make explicit a framework for challenging the way we think about education and the way it unfolds in an on-line environment.

\section{ABOUT THE AUTHOR}

Marc Schwartz is Professor of Mind, Brain and Education at the University of Texas at Arlington. He is also director of the Southwest Center for Mind, Brain and Education at UTA, which seeks to identify and support promising research agendas at the intersection of neuroscience and cognitive science to inform (and be informed by) educational practice and leadership.

Dr. Schwartz is a charter member of the International Mind, Brain and Education Society (IMBES), past vice president, and current president. The mission of IMBES is to facilitate cross-cultural collaboration in biology, education and the cognitive and developmental sciences. Dr. Schwartz is also an Associate Researcher in the Science Education Department at the Harvard-Smithsonian Center for Astrophysics (CfA).

\section{REFERENCES}

1. AAAS. 2001. Atlas of Science Literacy: Project 2061. Washington D.C.: American Association for the Advancement of Science.

2. Bransford, John D., Ann L. Brown, and Rodney R. Cocking, eds. 2000. How People Learn: Brain, Mind, Experience and School. Washington D.C.: National Academy Press.

3. Case, Robbie. 1987. The structure and process of intellectual development. International Journal of Psychology 22:571-607. 
4. Commons, M.L., E.J. Trudeau, S.A. Stein, S.A. Richards, and S.R. Krause. 1998. Hierarchical complexity of tasks shows the existence of developmental stages. Developmental Review 18 (237-278).

5. Csikszentmihalyi, M. 1990. Flow: The psychology of optimal experience. New York: Harper \& Collins.

6. Dawson-Tunik, Theo L., Michael Commons, Mark Wilson, and Kurt W. Fischer. 2005. The shape of developoment. European Journal of Developmental Psychology 2 (2):163-195.

7. De Corte, Erik. 2012. Constructive, self-regulated, situated, and collaborative learning: An approach for the acquisition of adaptive competence. Journal of Education 192 (2):33-47.

8. Doucerain, Marina, and Marc S. Schwartz. 2010. Analyzing learning about conservation of matter in students while adapting to the needs of a school. Mind, Brain and Education 4 (3):112-124.

9. Elgin, Catherine. 2006. From knowledge to understanding In Epistemology futures, edited by S. Hetherington. Oxford: Clarendon.

10. Elman, Jeffrey, E.A. Bates, J.H. Johnson, A Karmiloff-Smith, D Parisi, and K. Plunkett. 1996. Rethinking Innateness: A Connectionist Perspective on Development. Cambridge, MA: MIT Press.

11. Epstein, Lewis, and Paul G Hewitt. 1981. Thinking physics: Practical lessons in critical thinking. . San Francisco: Insight Press.

12. Fischer, K.W., D. Bullock, E.J. Rotenberg, and P. Raya. 1993. The dynamics of competence: How context contributes directly to skill. In Development in context: Acting and thinking in specific environments, edited by R. Wozniak and K. W. Fischer. Hillsdale, N.J.: Erlbaum.

13. Fischer, Kurt W., and Thomas R. Bidell. 1998. Dynamic development of psychological structures in action and thought. In Handbook of child psychology: Theoretical models of human development, edited by W. Damon and R. M. Lerner. New York, NY: John Wiley \& Sons.

14. Fuster, Joaquín M. 2009. Cortex and memory: Emergence of a new Paradigm. Journal of Cognitive Neuroscience 21 (11):2047-2072.

15. Gates, Bill, and Microsoft. 2013. Innovation \& Opportunity- The contribution of computing to improving our world In Virtual Faculty Summit. Redmond: Microsoft.

16. Gladwell, Malcom. 2008. Outliers: The story of success. New York: Little, Brown and Company.

17. Granott, Nira, Kurt W. Fischer, and James Parziale. 2002. Bridging to the unknown: A transition mechanism in learning and problem-solving. In Microdevelopment: Transition processes in development and learning, edited by N. Granott and J. Parziale. Cambridge, UK: Cambridge University Press.

18. Griffin, M.M. 1995. You can't get there from here: Situated learning, transfer, and map skills. Contemporary Educational Psychology 20 (1):65-87.

19. Hewitt, Paul. G. 2010. Conceptual Physics. Boston, MA: Addison-Wesley Publishing.

20. Jordan, Katy. 2013. Synthesising MOOC completion rates. In MoocMoocher: WordPress.com.

21. Kahneman, Daniel. 2011. Thinking, fast and slow. New York: Farrar, Straus and Giroux.

22. Klahr, David. In Press. Beyond Piaget: A perspective from studies of children's problem solving abilities. In Refreshing Developmental Psychology: Beyond the Classic Studies, edited by A. Slater and P. Quinn. London: Sage Publishers.

23. Koh, Adeline. 2013. Weekend reading: The MOOC catchup edition. The Chronicle of Higher Education, $\quad$ http://chronicle.com/blogs/profhacker/weekend-reading-the-mooc-catchupedition/50111.

24. Langer, Ellen J. 1997. The power of mindful learning. Reading, Massachusetts: Addison- Wesley.

25. Lave, Jean. 1993. Word problems: A microcosm of theories of learning. In Context and Cognition: Ways of learning and knowing, edited by P. Light and G. Butterworth. Hillsdale, N.J.: Lawrence Erlbaum Associates.

26. Nardi, B. 1996. Studying context: A comparison of activity theory, situated action models, and distributed cognition. In Context and consciousness: Activity theory and human-computer interaction, edited by B. Nardi. Cambridge, MA: MIT Press. 
27. Perkins, David. 1992. Smart schools: From training memories to educating minds. New York: The Free Press.

28. Piaget, J. 1983. Piaget's theory. In Handbook of child psychology, edited by P. M. Mussen. New York: Wiley.

29. Piaget, Jean. 1985. The equilibration of cognitive structures: The central problem of intellectual development. Translated by T. T. Brown \& K. J. Thampy. Chicago, IL: The University of Chicago Press.

30. Posner, Michael, and Mary Rothbart. 2006. Educating the human brain, Human Brain Development Series. Washington, D.C.: American Psychological Association.

31. Powers, W. 1973. Perceptual Control Theory. Hawthorne, NY: Aldine DeGruyter.

32. Powers, William. 1998. Making sense of behavior- The meaning of control. New Canaan, CT: Benchmark Publications Inc.

33. Rees, Jonathan. 2013. The MOOC racket. Slate.

34. Schank, Roger. 2011. Teaching mInds: How cognitive science can save our schools. New York: Teachers College Press.

35. Schank, Roger, and Chip Cleary. 1995. Engines for education. Hillsdale, NJ: Lawrence Erlbaum Associates.

36. Schwartz, Marc S. 2009. Cognitive development and learning: Analyzing the building of skills in classrooms. Mind, Brain and Education 3 (4):198-208.

37. Schwartz, Marc S., and Kurt Fischer, W. 2003. Building vs. Borrowing: The challenge of actively constructing ideas. Liberal Education (Summer):22-29.

38. Schwartz, Marc S., and Philip S. Sadler. 2001. Goals and technology education: The example of design challenges. Paper read at Proceedings of the Second AAAS Research in Technology Education Conference, at Washington D.C.

39. Repeated Author. 2007. Empowerment in science curriculum development: A microdevelopmental approach. . International Journal of Science Education 29 (18):987-1017.

40. Siegler, Robert S. 1996. Emerging minds: The process of change in children's thinking. New York, NY: Oxford University Press.

41. Tai, Robert H., and Philip S. Sadler. 2007. High school chemistry instructional practices and their association with college chemistry grades. Journal of Chemical Education 84 (6):1040-1046.

42. van Geert, Paul. 1998. A dynamic systems model of basic developmental mechanisms: Piaget, Vygotsky, and beyond. Child Development 105:634-677.

43. Wertsch, J.V., Minick, N., \& Arms, F.J. 1984. The creation of context in joint problem solving. In Everyday cognition: Its development in social context, edited by B. Rogoff and J. Lave. Cambridge, MA: Harvard University Press.

44. Wikipedia. Wile E. Coyote and the Road Runner. Wikipedia Foundation, Inc. 2013. Available from http://en.wikipedia.org/wiki/Wile E. Coyote and The Road Runner.

45. Wilson, Emily. 2013. The huge growth of MOOCs threatens America's great university system. Alternet, http://www.alternet.org/education/who-profitsmoocs?akid=10609.314356.jndowS\&rd=1\&src=newsletter858873\&t=7. 
Khan Academy: The Illusion of Understanding 